\title{
PERBANDINGAN METODE HOLT WINTER ADDITIVE DAN METODE HOLT WINTER ADDITIVE DAMPED DALAM PERAMALAN JUMLAH PENDAFTARAN MAHASISWA
}

\author{
I Made Ari Santosa, Ni Luh Ayu Kartika Yuniastari Sarja, Ratna Kartika Wiyati \\ $1,2,3$ STIKOM Bali \\ Jalan Raya Puputan No. 86 Renon, Bali \\ Email: ${ }^{1}$ dublut@yahoo.com, ${ }^{2}$ yuni@stikom-bali.ac.id, ${ }^{3}$ ratna@stikom-bali.ac.id
}

\begin{abstract}
ABSTRAK
Peramalan dapat diterapkan pada salah satu kegiatan yang dilaksanakan oleh perguruan tinggi yaitu STIKOM Bali tiap tahunnya yaitu penerimaan mahasiswa baru. Peramalan memang membantu dalam proses perencaan dan proses pengambilan keputusan, namun hasil peramalan tidaklah selalu akurat. Keakuratan hasil peramalan tergantung dengan ketepatan data dan metode yang digunakan. Pemilihan metode peramalan yang tepat penting dilakukan agar hasil peramalan tidak menyimpang. Mengacu pada permasalahan tersebut, penelitian yang dikembangkan menggunakan dua buah metode dalam melakukan peramalan jumlah pendaftaran mahasiswa baru yaitu Holt Winter Additive dan Holt Winter Additive Damped. Pada penelitian ini dilakukan uji coba hasil peramalan untuk membandingkan hasil kedua metode tersebut. Pengujian dilakukan dengan menggunakan sistem peralaman yang dikembangkan dan tolak ukur menggunakan nilai MAPE (Mean Absolute Percentage Error). MAPE menghitung jumlah persentase penyimpangan antara data aktual dan hasil peramalan. Tujuan penelitian ini adalah melakukan perbandingan hasil peramalan dari dua buah metode yang digunakan sehingga diketahui metode mana yang lebih tepat diterapkan untuk meramalkan jumlah pendaftaran mahasiswa baru. Metode Penelitian berupa pengembangan sistem, perhitungan peramalan, perhitungan nilai error, perbandingan nilai error dan pengambilan kesimpulan. Hasil dari penelitian yaitu dengan kasus peramalan jumlah pendaftaran mahasiswa baru perhitungan nilai MAPE metode holt winter additive lebih baik dibandingkan dengan metode holt winter additive damped. Nilai MAPE tahun 2017 untuk metode holt winter additive adalah $1,039 \%$ sedangkan holt winter additive damped 1,363\%, begitu pula dengan tahun 2018 untuk metode holt winter additive adalah 0,793\% sedangkan holt winter additive damped 1,214\%.
\end{abstract}

Kata Kunci: peramalan, holt winter additive, holt winter additive damped, Mean Absolute Percentage Error (MAPE).

\section{A. PENDAHULUAN}

Peramalan merupakan suatu teknik untuk memperkirakan suatu nilai pada masa yang akan datang dengan memperhatikan data masa lalu maupun data saat ini [1]. Fungsi peramalan adalah untuk membantu perencaan dan pengambilan keputusan dimasa yang akan datang. Fungsi peramalan tersebut membuat peramalan banyak diterapkan diberbagai aspek kehidupan salah satunya pada perguruan tinggi.

STIKOM Bali merupakan salah satu perguruan tinggi swasta di Bali yang bergerak dibidang IT. STIKOM Bali juga menjadi perguruan tinggi yang banyak diminati oleh para siswa-siswi yang telah menyelesaikan pendidikan menengah atas. Peramalan dapat diterapkan pada salah satu kegiatan yang dilaksanakan oleh STIKOM Bali tiap tahunnya yaitu penerimaan mahasiswa baru. Kegiataan penerimaan mahasiswa baru di STIKOM Bali dibagi menjadi empat gelombang dan tiga periode pendaftaran untuk masing-masing program studi. Hasil peramalan ini dapat dijadikan acuan untuk menyiapkan sarana 
prasarana yang dibutuhkan untuk proses seleksi penerimaan mahasiwa baru.

Peramalan memang membantu dalam proses perencaan dan proses pengambilan keputusan, namun hasil peramalan tidaklah selalu akurat. Keakuratan hasil peramalan tergantung dengan ketepatan data dan metode yang digunakan. Langkah penting untuk menentukan metode peramalan adalah dengan mempertimbangkan jenis pola datanya, sehingga metode yang paling tepat dengan pola tersebut dapat diuji [2]. Untuk menghasilkan peramalan yang tepat perlu memperhatikan metode perhitungan yang digunakan. Oleh karena itu, pemilihan metode peramalan yang tepat penting dilakukan agar hasil peramalan tidak menyimpang. Mengacu pada permasalahan tersebut, penelitian yang dikembangkan menggunakan dua buah metode dalam melakukan peramalan jumlah pendaftaran mahasiswa baru yaituHolt Winter Additive dan Holt Winter Additive Damped. Pada penelitian ini dilakukan uji coba hasil permalan untuk membandingkan hasil kedua metode tersebut. Pengujian dliakukan dengan menggunakan tolak ukur nilai MAPE (Mean Absolute Percentage Error). MAPE menghitung jumlah persentase penyimpangan antara data aktual dan hasil peramalan sehingga diketahui nilai penyimpangan kedua metode tersebut. Selain itu, hasil pengujian yang dilakukan dapat diketahui metode mana yang lebih tepat diterapkan untuk meramalkan jumlah pendaftaran mahasiswa baru.

Beberapa referensi yang digunakan dalam penelitian ini sebagai berikut :

\section{a. Penelitian Terkait}

Penelitian terkait penggunaan Metode Holt Winter Additive dilakukan pada penelitian[3] menerapkan metode untuk membangun sistem yang dapat memprediksi jumlah produksi gas dan minyak.Metode Holt Winter Additivejuga diterapkan pada penelitian lainnya untuk memprediksi kekeringan di Kabupaten Boyolali. Hasil perhitungan menunjukkan bahwa prediksi yang dihasilkan sudah dapat mengikuti bentuk dari pola data curah hujan daridata aktualdengan nilai error relatif kecil yaitu sebesat 5,44 [4]. Penelitian terkait penggunaan Metode Holt Winter Additive Damped untuk memprediksi jumlah penumpang pesawat pada Bandara Soekarno Hatta menunjukkan metode ini sudah mampu diterapkan dengan tingkat error yang rendah [5]. Penelitan [6] melakukan perbandingan hasil prediksi pasang surut air laut di wilayah Pelabuhan Tanjung Perak Surabaya dengan menggunakan metode simple exponential smoothing, holt exponential smoothing, damped exponential smoothing, dan winters additiveexponential smoothing. Hasil perhitungan menunjukkan bahwa model damped exponential smoothinglebih optimal digunakan untuk memprediksi pasang surut air laut di wilayah pelabuhan TanjungPerak Surabaya dengan nilai RMSE sebesar 0,119 , normalized $B I C$ sebesar -4,25 dan MAPEsebesar 8,04.

\section{b. Peramalan}

Peramalan merupakan suatu teknik untuk memperkirakan suatu nilai pada masa yang akan datang dengan memperhatikan data masa lalu maupun data saat ini. Akan tetapi, tidaklah berarti bahwa setelah mempelajari teknik ini, dapat meramal apa saja dengan tepat. Melainkan hanya mempelajari teknik tertentu yang dapat diaplikasikan pada situasi tertentu juga. Langkah penting dalam memilih suatu metode peramalan adalah dengan mempertimbangkan jenis pola data, sehingga metode yang paling tepat dengan pola tersebut dapat diuji [1] [2].

\section{c. Metode Holt Winter Additive}

Model musiman Additive dengan metode penambahan musiman cocok untuk prediksi deret berkala (time series) dengan amplitudo (atau ketinggian) pola musiman yang tidak tergantung pada rata-rata level atau ukuran data sehingga bersifat konstan [7]. Tiga persamaan yang digunakan dalam metodeHolt-Winters Additive adalah [2]:

$$
\begin{gathered}
S_{t}=\alpha\left(X_{t}-I_{t-1}\right)+(1-\alpha)\left(S_{t-1}+b_{t-1}\right) \\
b_{t}=\beta\left(S_{t}-S_{t-1}\right)+(1-\beta) b_{t-1} \\
I_{t}=\gamma\left(X_{t}-S_{t}\right)+(1-\gamma) I_{t-1}
\end{gathered}
$$


Dimana :

$$
Y_{t+m}=S_{t}+m b_{t}+I_{t-L+m}
$$

$S_{t}=$ Nilai pemulusan peramalan untuk periode $\mathrm{t}$

$X_{t}=$ Nilai aktual pada periode ke $\mathrm{t}$

$b_{t}=$ Nilai pemulusan trend

$I_{t}=$ Komponen musiman pada periode $\mathrm{t}$

$Y_{t+m}=$ Ramalan untuk $m$ periode depan dari $t$

$m=$ jumlah periode yang akan diramalakan

kedepan

$\alpha=$ Parameter penghalusan untuk trend $(0<\alpha<$

$\gamma=$ parameter penghalusan untuk trend $(0<\gamma<1)$

$\beta=$ Parameter penghalusan untuk trend $(0<\beta<$

1)

$L=$ Panjang Musiman

\section{d. Metode Holt Winter Additive Damped}

Metode Holt Winter Additive Damped ini merupakan modifikasi Holt winter linearmethod yang memperbolehkan adanya efek damping trend pada data. Dimana efek damping trend dengan menambahkan parameter $\varphi$ untuk memodifikasi komponentrend [8]. Adapun persamaannya sebagai berikut :

$$
\begin{gathered}
S_{t}=\alpha\left(X_{t}-I_{t-1}\right)+(1-\alpha)\left(S_{t-1}+\varphi b_{t-1}\right) \\
b_{t}=\beta\left(S_{t}-S_{t-1}\right)+(1-\beta) \varphi b_{t-1} \\
I_{t}=\gamma\left(X_{t}-S_{t}\right)+(1-\gamma) I_{t-1} \\
Y_{t+m}=S_{t}+\sum_{i=1}^{m} b_{t}+I_{t-L+m}
\end{gathered}
$$

Dimana :

- Jika $0<\varphi<1$, maka trend terendam dan nilai peramalan akan mendekati asimtot $S_{t}+\frac{\varphi}{1-\varphi} b_{t}$

\section{B. METODE PENELITIAN}

Tahapan peneltian yang dilakukan dapat dilihat pada Gambar 1.
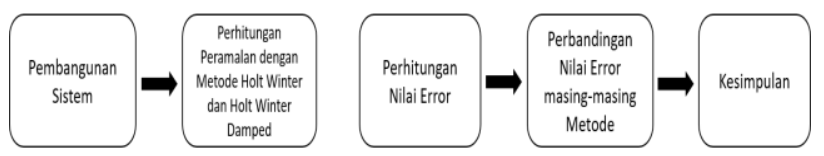

Gambar 1. Tahapan Penelitian

Gambar 1 menampilkan tahapan penelitian yang dilakukan. Adapun tahapan penelitian tersebut akan dijelaskan sebagai berikut.
- Jika $\varphi=1$, maka akan menjadi Holt Winter biasa

- Jika $\varphi=0$, maka akan menjadi Simple Exponential Smoothing

- Jika $\varphi>1$, maka fungsi peramalan mempunyai trend eksponensial

\section{e. Mean Absolute Percentage Error (MAPE)}

Mean Absolute Percentage Error (MAPE) dihitung dengan menggunakan kesalahan absolut pada tiap periode dibagi dengan nilai observasi yang nyata untuk periode itu. Kemudian, merata-rata kesalahan persentase absolut tersebut. MAPE merupakan pengukuran kesalahan yang menghitung ukuran presentase penyimpangan antara data aktual dengan data peramalan [9]. Nilai MAPE dapat dihitung dengan persamaan berikut.

Dimana :

$$
M A P E=\left(\frac{100 \%}{n}\right) \sum_{t=1}^{n} \frac{\left|X_{t}-F_{t}\right|}{X_{t}}
$$

$X_{t}=$ Data aktual pada periode $\mathrm{t}$

$F_{t}=$ Nilai Peramalan pada periode $\mathrm{t}$

$n=$ Jumlah Data

Kemampuan peramalan sangat baik jika memiliki nilai MAPE kurang dari $10 \%$ danmempunyai kemampuan peramalan yang baik jika nilai MAPE kurang dari $20 \%$.

\section{Pengembangan Sistem}

Tahapan pengembangan sistem dilakukan dengan menganalisa kebutuhan sistem, proses pengumpulan data yang akan digunakan yaitu data pendaftaran mahasiswa, perancangan sistem kemudian dilanjutkan dengan proses pengembangan sistem (koding).

2. Perhitungan Peramalan

Perhitungan proses peramalan dilakukan pada sistem menggunakan dua buah metode yaitu Holt Winter Additive dan Holt Winter Additive Damped. 


\section{Perhitungan Nilai Error}

Proses perhitungan nilai error dilakukan setelah mendapatkan hasil peramalan menggunakan kedua metode tersebut. Perhitungan nilai error menggunakan parameter Mean Absolute Percentage Error (MAPE).

4. Perbandingan Hasil Nilai Error

Perbandingan hasil nilai error dilakukan setelah mendapatkan nilai error untuk masingmasing metode. Perbandingan dilakukan untuk mendapatkan metode yang tepat.

\section{Kesimpulan}

Kesimpulan diambil berdasarkan hasil perbandingan nilai error untuk masing-masing metode.

\section{HASIL DAN PEMBAHASAN}

Pada tahap pertama yaitu pembangunan sistem dihasilkan sistem peramalan menggunakan bahasa pemrograman PHP dan database MySQL. Sistem ini digunakan dalam melakukan perhitungan peramalan dan nilai error. Data uji coba yang digunakan adalah data pendaftaran mahasiswa baru untuk program studi sistem informasi tahun 2017 dan tahun 2018. Data uji coba tersebut dapat dilihat pada Gambar 2 dan Gambar 3.

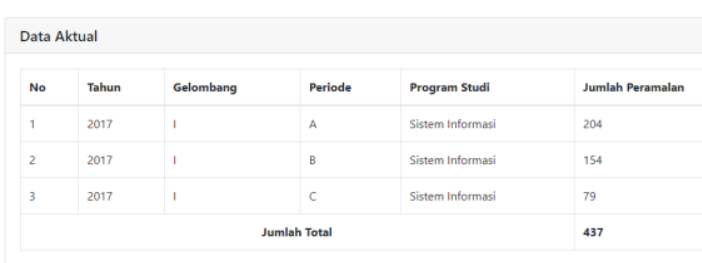

Gambar 2. Data Tahun 2017

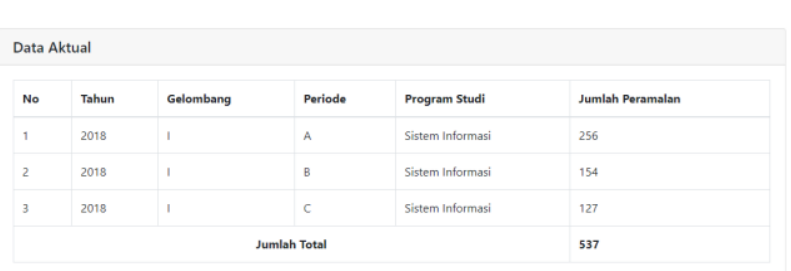

Gambar 3. Data Tahun 2018

Gambar 2 dan Gambar 3 menampilkan data aktual pendafataran mahasiswa program studi sistem informasi pada tahun 2017 dan 2018. Hasil perbandingan data aktual dengan data peramalan menggunakan metode Holt Winter Additive dan Holt Winter Additive Damped untuk tahun 2017 dapat dilihat pada Gambar 4.
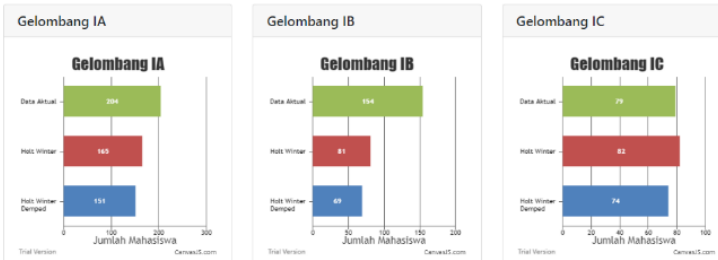

Gambar 4. Perbandingan Data Aktual dengan Hasil Peramalan Tahun 2017

Perbandingan data aktual dan data hasil peramalan ditampilkan pada Gambar 4. Data aktual untuk gelombang IA adalah 204, hasil peramalan holt winteradditive adalah 165 dan hasil peramalan holt winter additive damped adalah 151. Data aktual untuk gelombang IB adalah 154, hasil peramalan holt winteradditive adalah 81 dan hasil peramalan holt winter additive damped adalah 69. Data aktual untuk gelombang IC adalah 79, hasil peramalan holt winteradditive adalah 82 dan hasil peramalan holt winter additive damped adalah 74 .

Hasil perbandingan data aktual dengan data peramalan menggunakan metode Holt Winter Additive dan Holt Winter Additive Damped untuk tahun 2018 dapat dilihat pada Gambar 5.
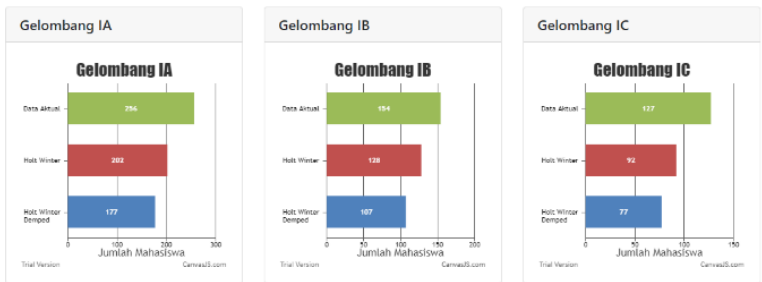

Gambar 5. Perbandingan Data Aktual dengan Hasil Peramalan Tahun 2018

Perbandingan data aktual dan data hasil peramalan ditampilkan pada Gambar 5. Data aktual untuk gelombang IA adalah 256, hasil peramalan holt winteradditive adalah 202 dan hasil peramalan holt winter additive 
dampedadalah 177. Data aktual untuk gelombang IB adalah 154, hasil peramalan holt winteradditive adalah 128 dan hasil peramalan holt winter additive damped adalah 107. Data aktual untuk gelombang IC adalah 127, hasil peramalan holt winteradditive adalah 92 dan hasil peramalan holt winter additive damped adalah 77.

Pengukuran ketepatan peramalan dilakukan dengan menghitung nilai error atau penyimpangan untuk masing-masing metode dengan menggunakan parameter Mean Absolute Percentage Error (MAPE). Perhitungan nilai error pada tahun 2017 dapat dilihat pada Gambar 6.

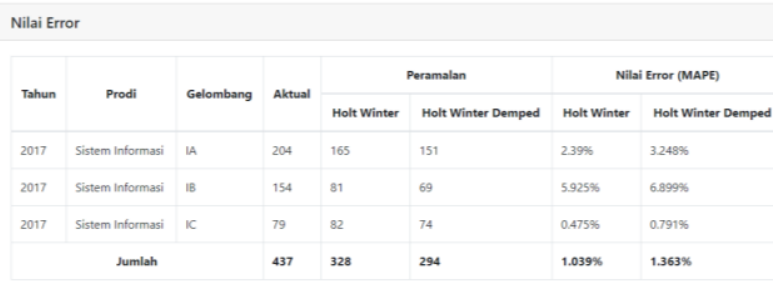

Gambar 6. Nilai MAPE untuk Tahun 2017

Gambar 6 menampilkan hasil perhitungan nilai error menggunakan MAPE dengan jumlah nilai error untuk metode holt winter additive adalah 1,039\% sedangkan untuk metode holt winter additive damped adalah 1,363\%. Perhitungan nilai error pada tahun 2018 dapat dilihat pada Gambar 7.

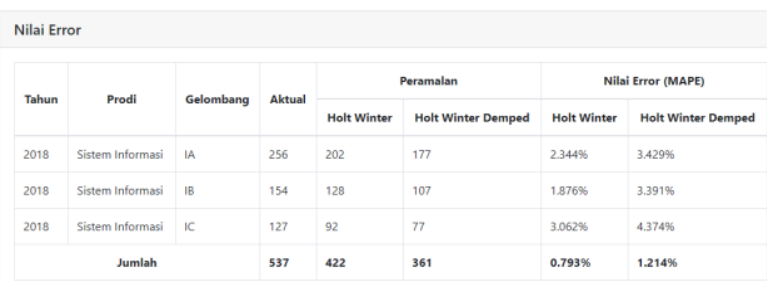

Gambar 7. Nilai MAPE untuk Tahun 2018

Gambar 7 menampilkan hasil perhitungan nilai error menggunakan MAPE dengan jumlah nilai error untuk metode holt winter additive adalah $0,793 \%$ sedangkan untuk metode holt winter additive damped adalah 1,214\%.
Berdasarkan hasil perhitungan di atas dapat disimpulkan bahwa metode yang tepat untuk melakukan peramalan pendaftaran mahasiswa baru adalah metode holt winter additive. Metode holt winter additivememiliki nilai error atau penyimpangan yang lebih kecil dibanding metode holt winter additive damped baik pada tahun 2017 maupun tahun 2018.

\section{KESIMPULAN}

Berdasarkan hasil perhitungan yang telah dilakukan baik metode holt winter additive maupun holt winter additive damped dapat diterapkan untuk melakukan peramalan jumlah pendaftaran mahasiswa baru, namun berdasarkan hasil perbandingan yang dilakukan dengan perhitungan nilai MAPE metode holt winter additive lebih baik dibandingkan dengan metode holt winter additive damped. Nilai MAPE tahun 2017 untuk metode holt winter additive adalah 1,039\% sedangkan holt winter additive damped $1,363 \%$, begitu pula dengan tahun 2018 untuk metode holt winter additive adalah $0,793 \%$ sedangkan holt winter additive damped $1,214 \%$.

\section{REFERENSI}

[1] Aswi dan Sukarna. (2006). Analisis Deret Waktu: Teori dan Aplikasi. AndiraPublisher: Makassar.

[2] Makridakis, S., Wheelwright, Steven C., McGee, Victor E. (2003). Metode danAplikasi Peramalan. Jilid 1. EdisiRevisi. Binarupa Aksara: Jakarta.

Sasongko. R, Prasetyo. E, Purbaningtyas. R. (2017). System Production PT. VICO Indonesia Using Method Holt Winters. Journal of Electrical Engineering and Computer Sciences. 2(1). pp. 221-230.

[4] Putra. D, Hartono. K., Tanone. R. (2018). Model Prediksi Kekeringan Menggunakan Metode Holt-Winters (Studi KAsus: Wilayah Kabupaten Boyolali). ICM Indonesian Journal of Computing and Modeling. pp. 36-41. 
[5] Primandari. A.H. (2016). An Alternative Forecasting Using Holt-Winter Damped Trend for Soekarno-Hatta Paseenger Volume. Eksakta: Jurnal Ilmu-ilmu MIPA. pp. 1-10.

[6] Asyhar. A. H, Febrianti. F, Fajriyah. N. R. (2018). Analisis Model Exponential Smoothing Terhadap Prediksi Pasang Surut Air Laut di Wilayah Pelabuhan Tanjung Perak Surabaya. Jurnal Sains Matematika dan Statistika. 4(1). pp. 915.
[7] Montgomery, C. Douglas. 2009. Statistical Quality Control (6th ed). Asia:JohnWiley \&Sons (Asia) Pte. Ltd.

[8] Gardner. Jr, E. S. and E. McKenzie. (1985) Forecasting trends in time series. Management Science. 31(10). pp. 12371246.

[9] Pakaja. F, Naba. A, Purwanto. (2012).Peramalan Penjualan Mobil Menggunakan JaringanSyaraf Tiruan dan Certainty Factor. Jurnal EECCIS. 6(1). 